\title{
Microindentation Hardness-Secondary Dendritic Spacings Correlation with Casting Thermal Parameters in an Al-9wt.\%Si Alloy
}

\author{
Diego CARVALHO ${ }^{2}$, José RODRIGUES ${ }^{1}$, Daniele SOARES ${ }^{1}$, Júlio AVIZ ${ }^{1}$, \\ André BARROS ${ }^{1}$, Maria SILVA ${ }^{1}$, Otávio ROCHA ${ }^{1,2}$, Ivaldo FERREIRA ${ }^{1}$, \\ Antonio MOREIRA ${ }^{1 *}$
}

\author{
${ }^{1}$ Institute of Technology, Federal University of Pará, UFPA, 66075-110, Belém, PA, Brazil \\ ${ }^{2}$ Federal Institute of Education, Science and Technology of Pará, IFPA, 66093-020, Belém, PA, Brazil
}

crossref http://dx.doi.org/10. 5755/j01.ms.24.1.17319

Received 22 December 2016; accepted 01 May 2017

\begin{abstract}
Experiments were carried out to analyze the effect of growth rates $\left(V_{\mathrm{L}}\right)$ and cooling rates $\left(T_{\mathrm{R}}\right)$ on both secondary dendritic arm spacings $\left(\lambda_{2}\right)$ and Vickers microhardness (HV) of an Al-9wt.\%Si alloy during the horizontal directional solidification under transient heat flow conditions. A water-cooled solidification experimental apparatus was developed allowing a wide range of $T_{\mathrm{R}}$ (from 0.2 to $3.5^{\circ} \mathrm{C} / \mathrm{s}$ ) to be experienced. Five computer guided thermocouples were connected with the metal, and the time-temperature data were recorded automatically. The solidification path was also calculated by Scheil model in Thermo-Calc software. Casting samples were characterized by the combined analyses of optical microscopy $(\mathrm{OM})$ and scanning electron microscopy coupled with energy dispersive spectrometry (SEM-EDS) revealing a complex arrangement of phases including $\alpha$-Al dendrites, Si particles and Fe-rich phases within interdendritic regions. It was observed that power law functions characterize the variation of $\lambda_{2}$ as a function of $V_{\mathrm{L}}$ and $T_{\mathrm{R}}$ with exponents of $-2 / 3$ and $-1 / 3$, respectively. Finally, experimental laws of power and Hall-Petch types are proposed relating the resulting HV to the $\lambda_{2}$. According to these results, it was found that, for increasing values of $\lambda_{2}$, the results of HV decrease.

Keywords: solidification, thermal parameters, dendrite arm spacings, microhardness.
\end{abstract}

\section{INTRODUCTION}

The commercial importance of Al-Si alloys is based on its high fluidity and low shrinkage in casting, brazing and welding applications, in addition to its high specific strength and good corrosion resistance [1]. The microstructure of Al-Si alloys consists of $\alpha$-Al dendrites, $\mathrm{Al}-\mathrm{Si}$ eutectic and other phases by presence of $\mathrm{Mn}, \mathrm{Fe}, \mathrm{Mg}$, $\mathrm{Cu}$ and other elements. Aluminum alloys with even small amounts of iron causes formation of intermediate Fe-rich phases [2]. It is also important to highlight that casting is a complicated process which involves considerable mechanical and metallurgical aspects. The cooling rate, for instance, governs the microstructure to a large extent which in turn controls mechanical properties such as hardness, ultimate tensile strength, toughness, fatigue resistance, ductility, yield tensile strength and machinability of solidified alloys [3-5].

On the other hand, dendritic growth is perhaps the most frequently observed phenomenon during the solidification whose morphology is characterized by primary $\left(\lambda_{1}\right)$, secondary $\left(\lambda_{2}\right)$ and tertiary $\left(\lambda_{3}\right)$ dendrite arm spacings. It has long been established that dendrite fineness can be of even more importance than the grain size for the improvement of mechanical properties. Dendritic growth is controlled by the complex interplay of thermal, solutal, capillary, thermodynamics and kinetics properties which occur on different length scales. Several approaches and equations have been used with the purpose of modeling

\footnotetext{
* Corresponding author. Tel.: +55-91-32017251.

E-mail address: alsm@ufpa.br (A. Moreira)
}

both theoretically and experimentally the dendritic arm spacings as a function of alloy solute concentration, type of mold, melt superheat, growth rate $\left(V_{\mathrm{L}}\right)$, temperature gradient ahead of the solidification front $\left(G_{\mathrm{L}}\right)$ and cooling rate in the melt $\left(T_{\mathrm{R}}\right)[6-11]$. Therefore, dendritic growth direction with respect to the gravity vector during directional solidification of metallic alloys can also be considered as an important object of investigation.

The main purpose of this work is to investigate the influence of solidification thermal parameters i.e., $V_{\mathrm{L}}$ and $T_{\mathrm{R}}$ which affect the microstructure, on both secondary dendritic arm spacings $\left(\lambda_{2}\right)$ and Vickers microhardness (HV) of Al-9wt.\%Si alloy during the horizontal directional solidification under unsteady-state heat flow conditions. Experimental laws of power and Hall-Petch types are proposed relating the resulting microhardness to the secondary dendritic arm spacings.

\section{EXPERIMENTAL PROCEDURE}

Experiments were carried out with Al-9wt.\%Si hypoeutectic alloy. The thermophysical properties of this alloy as well as the chemical compositions of metals that were used to prepare the alloy investigated have been detailed in a previous article [12]. The casting assembly used in unsteady-state horizontal directional solidification experiments was designed in such a way that the heat was extracted only through a water-cooled system placed in the lateral mold wall, promoting horizontal directional solidification. A stainless steel mold used was $110 \mathrm{~mm}$ long, $70 \mathrm{~mm}$ wide, $60 \mathrm{~mm}$ high and $3 \mathrm{~mm}$ thick. The thermal contact condition at the metal-mold interface was 
also standardized with the heat-extracting surface being polished. The lateral inner mold walls were covered with a layer of insulating alumina and the upper part of the mold was closed with refractory material to minimize heat losses from the mold to a minimum.

Continuous temperature measurements were made during solidification at different positions in the casting and the data were acquired automatically. For the measurements a set of 5 fine type $\mathrm{K}$ thermocouples, accurately located with respect to the metal-mold interface, were connected by coaxial cables to a data logger interfaced with a computer, and the temperature data were acquired automatically. Approaching the working temperature (10\% above the liquidus temperature), the mold was taken from the heater and set immediately on a water-cooled stainless steel chill. Water circulated through this cooling jacket keeping the stainless steel plate during the solidification at a constant temperature of about $25^{\circ} \mathrm{C}$ and thus inducing a longitudinal heat transfer from the mold. Solidification occurred dendritically from the lateral chill surface, forming a columnar structure. After this, the metallographic specimens were mechanically polished with abrasive papers and subsequently etched with an acid solution composed of $5 \mathrm{ml} \mathrm{H} 2 \mathrm{O}, 60 \mathrm{ml} \mathrm{HCl}, 30 \mathrm{ml} \mathrm{HNO}_{3}$ and $5 \mathrm{ml} \mathrm{HF}$ to reveal the microstructure. Etching was performed at a temperature between $30^{\circ} \mathrm{C}$ and $35^{\circ} \mathrm{C}$ during approximately 10 minutes.

Selected longitudinal (parallel to the growth direction) sections of the directionally solidified specimens at 5,10 , $15,30,40,50,60$ and $70 \mathrm{~mm}$ from the metal-mold interface were electropolished and etched with a solution of $5 \% \mathrm{HF}$ in water for micrograph examination. Image processing system Olympus BX51 and Image Tool (IT) software were used to measure secondary arm spacings (about 20 independent readings for each selected position, with the average taken to be the local spacings) and their distribution range. The secondary arm spacings were measured by averaging the distance between adjacent sidebranches on the longitudinal section of a primary dendrite [13] as can be seen in Fig. 1 .

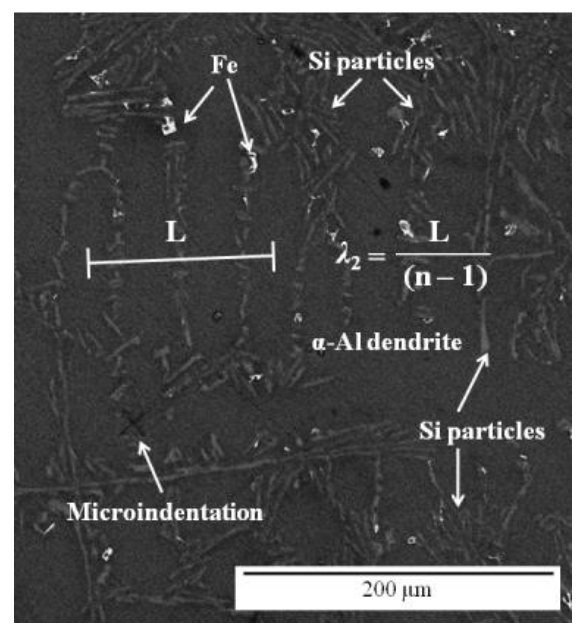

Fig. 1. Measurement procedure for $\lambda_{2}$ in a SEM micrograph ( $\mathrm{L}$-length; $\mathrm{n}$-number of secondary arms)

Furthermore, microstructural characterization was performed using a scanning electron microscope (SEM Shimadzu, VEGA 3 SBU TESCAM) coupled to an energy dispersion spectrum (EDS AZTec Energy X-Act, Oxford). The Thermo-Calc software was used to generate the solidification path for the analyzed alloy considering Scheil model.

Microhardness measurements in this study were carried out using by Shimadzu HMV-2 model hardness measuring test device using a $50 \mathrm{~g}$ load and a dwell time of $10 \mathrm{~s}$. The microhardness values were measured at least 20 different regions on longitudinal section.

\section{RESULTS AND DISCUSSION}

Fig. 2 presents microstructures of longitudinal section of samples at 5, 30, and $60 \mathrm{~mm}$ from metal-mold interface, showing the secondary dendrite arms. The dendrite arm spacings were sufficiently distinct to make reasonably accurate measurements along the casting length.

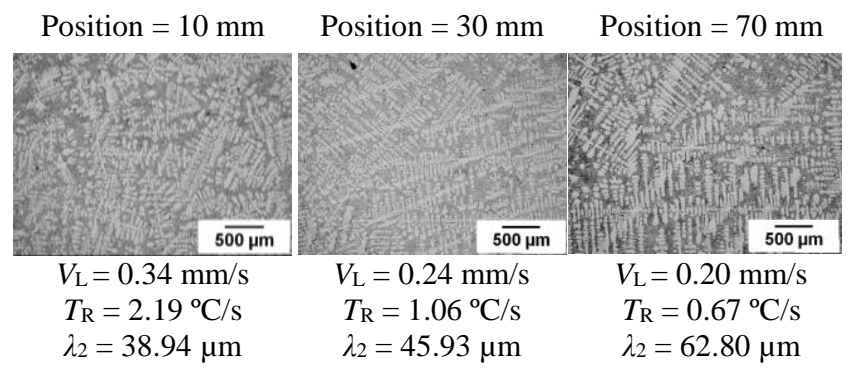

Fig. 2. Micrographs of directionally solidified Al-9wt.\%Si alloy longitudinal section showing the variation in secondary interdendric spacings with the distance from the metalmold interface

Fig. 3 shows the average experimental values of secondary dendritic spacings as a function of distance from the cooled stainless steel chill obtained in this work. It is observed that these dendrite arm spacings increase with the distance from the heat-extracting surface of Al-Si alloy investigated.

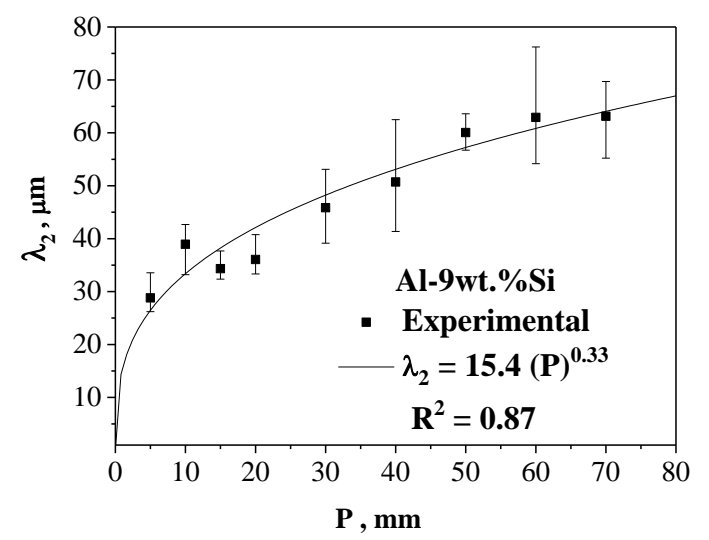

Fig. 3. Secondary dendrite arm spacings as a function of distance from metal-mold interface

The dendrite arm spacings are dependent on solidification thermal parameters such as $V_{\mathrm{L}}$ and $T_{\mathrm{R}}$, which vary with time and position during solidification. In order to determine more accurate values of these thermal parameters as a function of position from the metal-mold interface, the results of experimental thermal analysis have been used to determine the displacement of the liquidus isotherm, i.e., the thermocouples readings have also been 
used to generate a plot of position from the metal-mold interface as a function of time corresponding to the liquidus front passing by each thermocouple.

A curve fitting technique on such experimental points has generated a power function of position as a function of time. The derivative of this function with respect to time has yielded values for $V_{\mathrm{L}}$. On the other hand, the $T_{\mathrm{R}}$ profile was calculated by considering the thermal data recorded immediately after the passing of the liquidus front by each thermocouple. It was found that the water-cooled mold imposes higher values of $V_{\mathrm{L}}$ and $T_{\mathrm{R}}$ near the metal-mold interface and a decreasing profile along the casting due to the increasing thermal resistance of the solidified shell with distance from the cooled surface, as expected. The experimental results of $V_{\mathrm{L}}$ and $T_{\mathrm{R}}$ were compared with the theoretical predictions furnished by a numerical solidification model [14] and a good agreement has been observed between the experimental values of these thermal parameters and those numerically simulated for the alloy examined [12], as can be seen in Fig. 4.

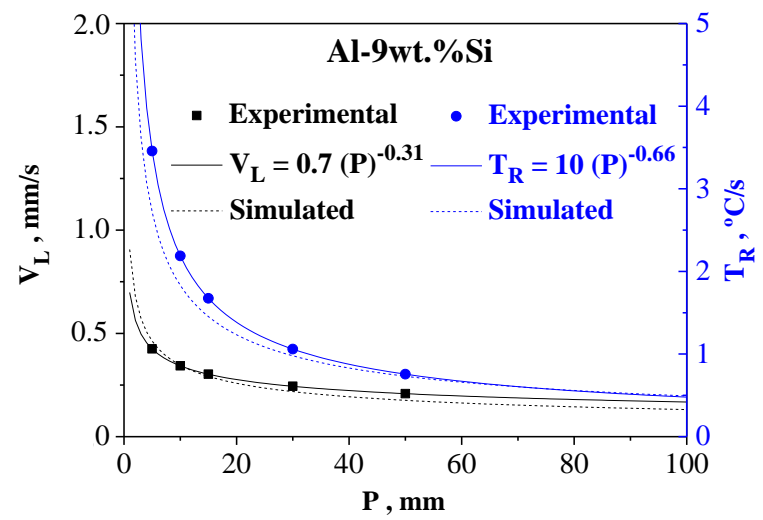

Fig. 4. $V_{\mathrm{L}}$ and $T_{\mathrm{R}}$ profiles as functions of position from metalmold interface

Although the numerical model [14] employed for $V_{\mathrm{L}}$ and $T_{\mathrm{R}}$ theoretical estimation does not take effects on convection in liquid into account, it was selected from the literature as the most appropriate model for representing the solidification conditions considered in this article. Moreover, it has been frequently used by other authors in researching directional solidification which produce melt convection effects [14-17]. In order to correlate the secondary dendrite arm spacings measured from the aforementioned microstructures with solidification thermal parameters, these spacings are plotted as a function of $V_{\mathrm{L}}$ and $T_{\mathrm{R}}$ in Fig. 5 and Fig. 6, respectively. The average dendritic spacings along with the standard variation are presented in these figures, with the lines representing an experimental power function fit with the experimental points.

As shown in Fig. 5, the secondary dendrite arm spacings were found to decrease as the $V_{\mathrm{L}}$ is increased. Most of the results from the literature pertaining to $\lambda_{2}$ in hypoeutectic alloys also indicate a decrease in spacings with decreasing $V_{\mathrm{L}}$. Furthermore, a power law function characterizes the experimental variation of secondary spacings with $V_{\mathrm{L}}$ with an index of $-2 / 3$, i.e., $\lambda_{2} \alpha V_{\mathrm{L}}{ }^{-2 / 3}$. It can be observed in Fig. 6 that a $-1 / 3$ power law characterizes the experimental variation of secondary spacings with $T_{\mathrm{R}}$.

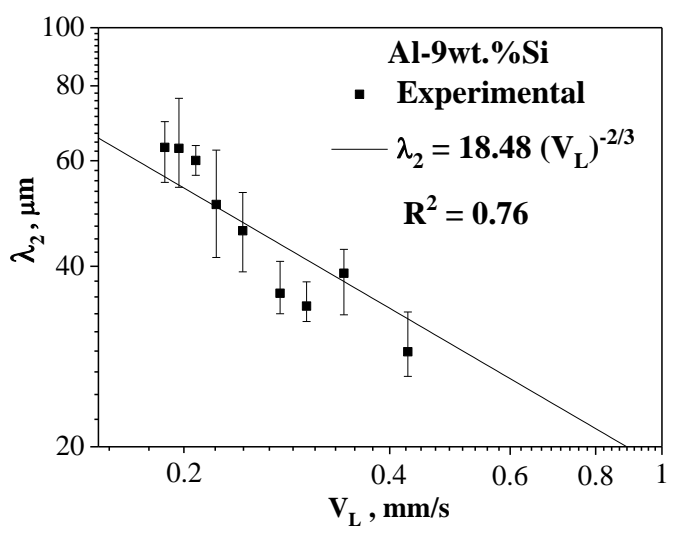

Fig. 5. Secondary dendrite arm spacings as a function of $V_{\mathrm{L}}$

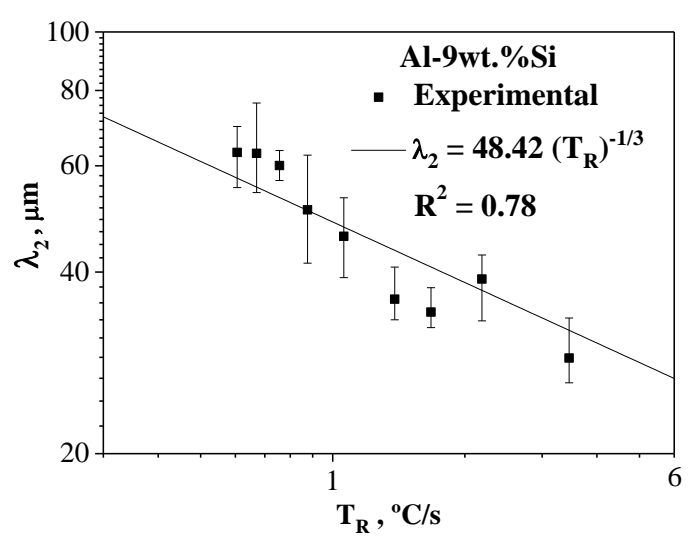

Fig. 6. Secondary dendrite arm spacings as a function of $T_{R}$

This is in agreement with observations reported by Rocha et al. [9] and Peres et al. [18] that exponential relationships $\lambda_{2}=$ constant $\left(V_{L}\right)^{-2 / 3}$ best generate the experimental variation of secondary dendritic arms with growth rate along the unsteady-state upward vertical directional solidification of $\mathrm{Al}-\mathrm{Cu}, \mathrm{Sn}-\mathrm{Pb}$ and $\mathrm{Al}-\mathrm{Si}$ alloys. These same exponential relationships have also been observed for other systems of non-ferrous alloys independent of the growth direction, reinforcing the proper application of the exponents $-2 / 3$ and $-1 / 3$ to correlate the $\lambda_{2}$ evolution, respectively, with $\mathrm{V}_{\mathrm{L}}$ and $\mathrm{T}_{\mathrm{R}}$ [9, 18-22]. In a study published recently, Araújo et al. [23] have reported a detailed physical description of dendrite arms growth theoretical models as well as have shown obtained results of growth experimental laws of secondary dendrite arm spacing as a function of $\mathrm{V}_{\mathrm{L}}$.

The mechanical properties of any solidified material are usually monitored by hardness testing, which is one of the easiest and most straightforward techniques. In this sense, the average experimental values of microhardness as a function of secondary dendritic spacings of Al-9wt.\% $\mathrm{Si}$ alloy are plotted in Fig. 7 and Fig. 8 as well as experimental equations of power and Hall-Petch types have been fitted to the experimental scatter to correlate the resulting microhardness to the secondary dendritic arm spacings. It is important to mention that $\mathrm{R}^{2}$ value is a statistical measure of how well the regression line approximates the experimental data in regression. $\mathrm{R}^{2}=1$ indicates that the regression line perfectly fits the data. It 
can be observed that 0.7 value shows a good agreement between experimental and theoretical results. On the other hand, several studies have been published showing experimental laws of Hall-Petch type to relate the resulting $\mathrm{HV}$ to the $\lambda_{2}[22-25]$.

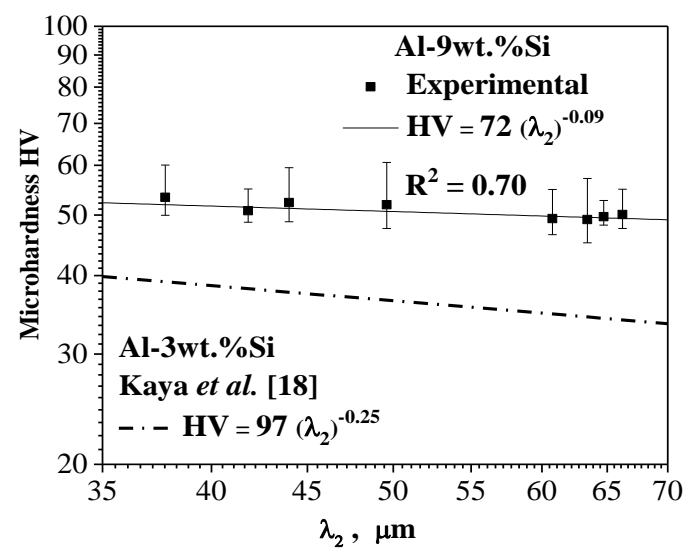

Fig. 7. Variation of microhardness as a function of $\lambda_{2}$ values

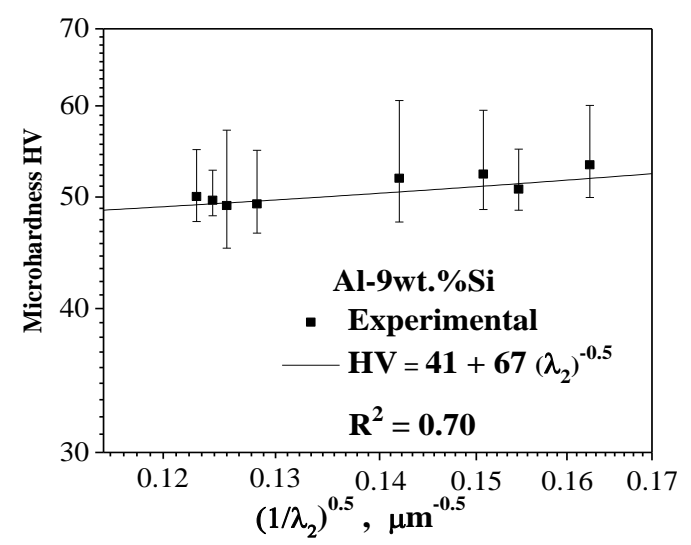

Fig. 8. Dependence of microhardness on the inverse of the square root of $\lambda_{2}$ values

It can be seen, as expected, that higher microhardness is associated with smaller secondary dendritic arm spacings. On the other hand, Kaya et al. [25], using Bridgman system, have developed investigations on relationships between the microindentation hardness (HV) and secondary dendrite arm spacings $\left(\lambda_{2}\right)$ during the course of upward directional solidification of Al-3wt.\%Si alloy. These authors have established a power type relationship given by equation $\mathrm{HV}=97\left(\lambda_{2}\right)^{-0.25}$, finding a value of " $\mathrm{n}$ " equal to -0.25 , different of that obtained in this work, as expected.

It can be clearly observed in Fig. 7 that $\mathrm{HV}$ values obtained by Kaya et al. [25] present a similar behaviour to those obtained in this work, i.e., in both cases $\mathrm{HV}$ is increased as $\lambda_{2}$ is decreased. However, the results obtained in this work throughout the solidification are more raised.

Considering the solidification path calculated by Scheil model in Thermo-Calc software (Fig. 9), it is possible to note an aluminum-rich matrix and an eutectic mixture formed by $\alpha-\mathrm{Al}+\mathrm{Si}+\beta$-AlFeSi. It is well known that low Fe concentration can be present in commercially pure $\mathrm{Al}$ and $\mathrm{Si}$ and may induces the formation of ironcontaining phases even in low fractions [26]. On the other hand, a typical SEM micrograph (Fig. 10) reveals as-cast microstructure consisted of $\alpha$ - $\mathrm{Al}$ dendrites as the primary phase with the presence of Si particles and Fe-rich phase segregation with 'chinese script' morphology. In Fig. 10 the points from 1 to 6 indicate the places where microanalysis by SEM-EDS were carried out.

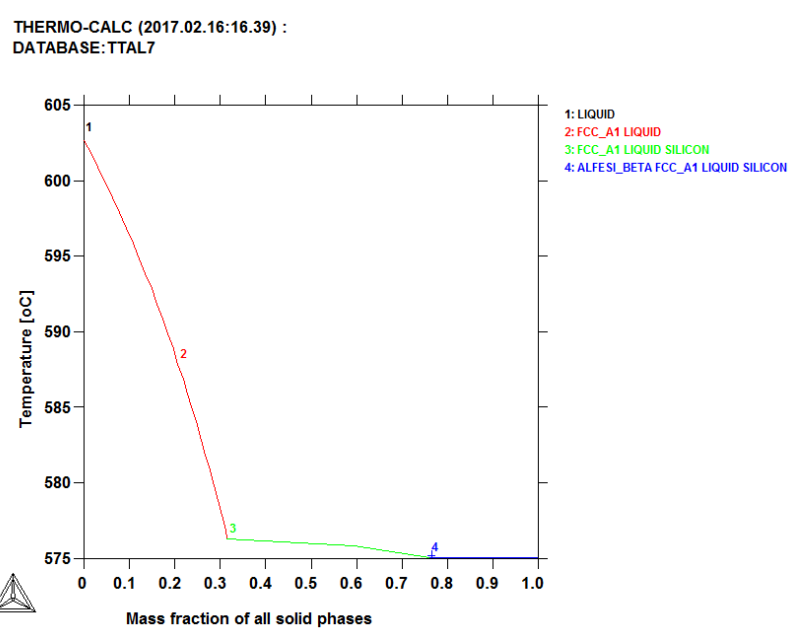

Fig. 9. Solidification path for the Al-9wt.\%Si-0.2wt.\%Fe alloy

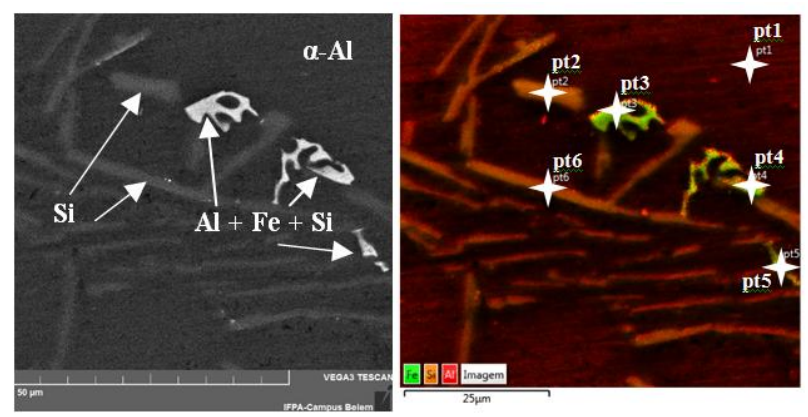

\begin{tabular}{|c|c|c|c|}
\hline \multirow{2}{*}{ Point } & \multicolumn{3}{|c|}{ Weigth, \% } \\
\cline { 2 - 4 } & $\mathrm{Al}$ & $\mathrm{Si}$ & $\mathrm{Fe}$ \\
\hline 1 & 98.68 & 1.32 & - \\
\hline 2 & 18.16 & 81.76 & 0.08 \\
\hline 3 & 65.55 & 8.38 & 26.07 \\
\hline 4 & 81.27 & 6.09 & 12.64 \\
\hline 5 & 77.96 & 5.47 & 16.57 \\
\hline 6 & 59.79 & 40.17 & 0.04 \\
\hline
\end{tabular}

Fig. 10. SEM micrograph at position of $10 \mathrm{~mm}$ from metal-mold interface $\left(V_{\mathrm{L}}=0.34 \mathrm{~mm} / \mathrm{s}, T_{\mathrm{R}}=2.19^{\circ} \mathrm{C} / \mathrm{s}, \quad \lambda_{2}=39 \mu \mathrm{m}\right)$ with the corresponding chemical microanalysis

\section{CONCLUSIONS}

The following major conclusions can be drawn from this study, where Al-9wt.\%Si alloy has been directionally solidified under unsteady-state heat flow conditions:

1. Secondary dendrite arm spacings were observed to increase with the distance from the heat-extracting surface of investigated alloy, as expected. The secondary dendrite arm spacings were found to decrease as both $V_{\mathrm{L}}$ and $T_{\mathrm{R}}$ are increased.

2. A power law function characterizes the experimental variation of secondary spacings with growth rate with an index of $-2 / 3$, i.e., $\lambda_{2} \alpha V_{\mathrm{L}}^{-2 / 3}$ as well as a $-1 / 3$ power 
law function characterizes the experimental values of secondary spacings with cooling rate, i.e., $\lambda_{2} \alpha T_{\mathrm{R}}{ }^{-1 / 3}$.

3. Higher HV results were found in regions in which the solidified alloy has tended to grow faster which are associated with smaller $\lambda_{2}$. Experimental equations of power and Hall-Petch types may be applied to characterize the experimental variation of HV results with $\lambda_{2}$ for the investigated Al-Si alloy.

4. SEM micrograph reveals as-cast microstructure consisted of $\alpha$-Al dendrites as the primary phase with the presence of $\mathrm{Si}$ particles and Fe-rich phase segregation with 'chinese script' morphology.

5. This work may contribute to the understanding of how to manage solidification operational parameters aiming at designing the microstructure of Al-based alloys.

\section{Acknowledgments}

The authors acknowledge the financial support provided by IFPA - Federal Institute of Education, Science and Technology of Pará, UFPA - Federal University of Pará, and CNPq - The Brazilian Research Council (grants 472745/2013-1 and 308784/2014-6), FAPESPA - Amazon Foundation of Support to Study and Research (grants ICAAF 064/2016) and CAPES - Coordination of Superior Level Staff Improvement, Brazil.

\section{REFERENCES}

1. Samuel, E., Samuel, A.M., Doty, H.W., Valtierra, S., Samuel, F.H. Intermetallic Phases in $\mathrm{Al}-\mathrm{Si}$ Based Cast Alloys: New Perspective International Journal of Cast Metals Research 27 2014: pp. 107-114.

https://doi.org/10.1179/1743133613Y.0000000083

2. Mikolajczak, P., Ratke, L. Thermodynamic Assessment of Mushy Zone in Directional Solidification Archives of Foundry Engineering 15 2015: pp. 101-109.

https://doi.org/10.1515/afe-2015-0088

3. Okamoto, T., Kishitake, K. Dendritic Structure in Unidirectionally Solidified Aluminium, Tin, and Zinc Base Binary Alloys Journal of Crystal Growth 29 1975: pp. $137-146$. https://doi.org/10.1016/0022-0248(75)90217-1

4. Kurz, W., Fisher, J.D. Dendrite Growth at the Limit of Stability: Tip Radius and Spacings Acta Metallurgica 29 1981: pp. $11-20$. https://doi.org/10.1016/0001-6160(81)90082-1

5. Venkatesan, A., Gopinath, V.M., Rajadurai, A. Simulation of Casting Solidification and Its Grain Structure Prediction Using FEM Journal of Materials Processing Technology 168 2005: pp. 10-15. https://doi.org/10.1016/j.jmatprotec.2004.09.090

6. McCartney, D.G., Hunt, J.D. Measurements of Cell and Primary Dendrite Arm Spacings in Directionally Solidified Aluminium Alloys Acta Metallurgica 29 1981: pp. $1851-1863$. https://doi.org/10.1016/0001-6160(81)90111-5

7. Bouchard, D., Kirkaldy, J.S. Scaling of Intragranular Dendritic Microstructure in Ingot Solidification Metallurgical and Materials Transactions B 27 1996: pp. $101-113$. https://doi.org/10.1007/BF02915081
8. Gündüz, M., Çadirli, E. Directional solidification of aluminium-copper alloys Materials Science and Engineering A 327 2002: pp 167-185. https://doi.org/10.1016/S0921-5093(01)01649-5

9. Rocha, O.L., Siqueira, C.A., Garcia, A. Heat Flow Parameters Affecting Dendrite Spacings During UnsteadyState Solidification of $\mathrm{Sn}-\mathrm{Pb}$ and $\mathrm{Al}-\mathrm{Cu}$ Alloys Metallurgical and Materials Transactions A 34 2003: pp. $995-1006$. https://doi.org/10.1016/S0921-5093(01)01649-5

10. Rocha, O.L., Siqueira, C.A., Garcia, A. Cellular/Dendritic Transition During Unsteady-State Unidirectional Solidification of $\mathrm{Sn}-\mathrm{Pb}$ Alloys Materials Science and Engineering A 347 2003: pp. 59-69. https://doi.org/10.1016/S0921-5093(02)00581-6

11. Wu, M., Ludwig, A., Fjeld, A. Modelling Mixed Columnar-Equiaxed Solidification with Melt Convection and Grain Sedimentation - Part II: Illustrative Modelling Results and Parameter Studies Computational Materials Science 50 2010: pp. $43-58$. https://doi.org/10.1016/j.commatsci.2010.07.006

12. Carvalho, D.B., Moreira, A.L., Moutinho, D.J., Filho, J.M., Rocha, O.L., Spinelli, J.E. The Columnar to Equiaxed Transition of Horizontal Unsteady-State Directionally Solidified Al-Si Alloys Materials Research 17 2013: pp. $498-510$. https://doi.org/10.1590/S1516-14392014005000015

13. Gündüz, M., Çadirli, E. Directional Solidification of Aluminium-Copper Alloys Materials Science and Engineering A 327 2002: pp. 167-185. https://doi.org/10.1016/S0921-5093(01)01649-5

14. Ferreira, I.L., Spinelli, J.E., Nestler, B., Garcia, A. Influences of Solute Content, Melt Superheat and Growth Direction on the Transient Metal/Mold Interfacial Heat Transfer Coefficient During Solidification of $\mathrm{Sn}-\mathrm{Pb}$ Alloys Materials Chemistry and Physics 111 2008: pp. 444-454. https://doi.org/10.1016/j.matchemphys.2008.04.044

15. Spinelli, J.E., Ferreira, I.L., Garcia, A. Evaluation of Heat Transfer Coefficients During Upward and Downward Transient Directional Solidification of Al-Si Alloys Structural and Multidisciplinary Optimization 31 2006: pp. $241-248$. https://doi.org/10.1007/s00158-005-0562-9

16. Cheung, N., Ferreira, I.L., Pariona, M.M., Quaresma, J.V., Garcia, A. Melt Characteristics and Solidification Growth Direction with Respect to Gravity Affecting the Interfacial Heat Transfer Coefficient of Chill Castings Materials and Design 30 2009: pp. $3592-3601$. https://doi.org/10.1016/j.matdes.2009.02.025

17. Cheung, N., Santos, N., Quaresma, J., Dulikravich, G., Garcia, A. Interfacial Heat Transfer Coefficients and Solidification of an Aluminum Alloy in a Rotary Continuous Caster International Journal of Heat and Mass Transfer 52 2009: pp. 451-459. https://doi.org/10.1016/j.jiheatmasstransfer.2008.07.003

18. Peres, M.D., Siqueira, C.A., Garcia, A. Macrostructural and Microstructural Development in Al-Si Alloys Directionally Solidified Under Unsteady-State Conditions Journal of Alloys and Compounds 381 2004: pp. $168-181$. https://doi.org/10.1016/j.jallcom.2004.03.107

19. Gomes, L.G., Moutinho, D.J., Ferreira, I.L., Rocha, O.L., Garcia, A. The Growth of Secondary Dendritic Arms in Directionally Solidified Al-Si-Cu Alloys: A Comparative 
Study with Binary Al-Si Alloys Applied Mechanics and Materials 719-720 2015: pp. 102-105.

https://doi.org/10.4028/www.scientific.net/AMM.719720.102

20. Costa, T.A., Moreira, A.L., Moutinho, D.J., Dias, M., Ferreira, I.L., Spinelli, J.E, Rocha, O.L, Garcia, A. Growth Direction and Si Alloying Affecting Directionally Solidified Structures of Al-Cu-Si Alloys Materials Science and Technology 31 2015: pp. 1103-1112. https://doi.org/10.1179/1743284714Y.0000000678

21. Spinelli, J.E., Rosa, D.M., Ferreira, I.L., Garcia, A. Influence of Melt Convection on Dendritic Spacings of Downward Unsteady-State Directionally Solidified Al-Cu Alloys Materials Science \& Engineering A 383 2004: pp. 271-282. https://doi.org/10.1016/S0921-5093(04)00831-7

22. Brito, C., Costa, T.A., Vida, T.A., Bertelli, F., Cheung, N., Spinelli, J.E., Garcia, A. Characterization of Dendritic Microstructure, Intermetallic Phases, and Hardness of Directionally Solidified Al-Mg and Al-Mg-Si Alloys Metallurgical and Materials Transactions A 46A 2015: pp 3342-3355.

https://doi.org/10.1007/s11661-015-2967-4
23. Araújo, E.C., Barros, A.S., Kikuchi, R.H., Silva, A.P., Gonçalves, F.A., Moreira, A.L., Rocha, O.L. The Role of $\mathrm{Si}$ and $\mathrm{Cu}$ Alloying Elements on the Dendritic Growth and Microhardness in Horizontally Solidified Binary and Multicomponent Aluminum-Based Alloys Metallurgical and Materials Transactions A 48A 2017: pp. 1163-1175. https://doi.org/10.1007/s11661-016-3942-4

24. Acer, E., Çadirli, E., Erol, H., Gündüz, M. Effect of Growth Rate on the Microstructure and Microhardness in a Directionally Solidified Al-Zn-Mg Alloy Metallurgical and Materials Transactions A 47A 2016: pp. 3040-3051. https://doi.org/10.1007/s11661-016-3484-9

25. Kaya, H., Çadirli, E., Böyük, U., Marasli, N. Variation of Microindentation Hardness with Solidification and Microstructure Parameters in the Al Based Alloys Applied Surface Science 255 2008: pp. 3071-3078. https://doi.org/10.1016/j.apsusc.2008.08.080

26. Costa, T.A., Dias, M., Gomes, L.G., Rocha, O.L, Garcia, A. Effect of Solution Time in T6 Heat Treatment on Microstructure and Hardness of a Directionally Solidified Al-Si-Cu Alloy Journal of Alloys and Compounds 683 2016: pp. $485-494$.

https://doi.org/10.1016/j.jallcom.2016.05.099 